\title{
About the thermomechanical behaviour of a carbon fibre reinforced high-temperature thermoplastic composite
}

\author{
Xavier Gabrion, Vincent Placet*, Frédérique Trivaudey, Lamine Boubakar \\ FEMTO-ST Institute, Department of Applied Mechanics, UMR CNRS 6174, University of \\ Bourgogne Franche-Comté, F-25000 Besançon, \\ *Email: vincent.placet@univ-fcomte.fr \\ tel: +33381.666 .055 fax: +33381.666 .700$
}

\begin{abstract}
Novel high-temperature thermoplastic polymers offer potential advantages over thermoset ones and represent a promising alternative in advanced composite applications. This work proposes to determine the thermal properties and resistance of unidirectional carbon fibre reinforced thermoplastic polyimide composite and to characterize the influence of temperature on its mechanical behaviour and properties, including tensile properties, interlaminar shear strength and failure mechanisms. Characterization is performed on composite tapes and on ring-shaped specimens manufactured using a heated-head thermoplastic filament winding process.

Results show that the thermal degradation of such composite material occurs at temperature higher than $400^{\circ} \mathrm{C}$. The glass transition temperature is approximately $250^{\circ} \mathrm{C}$. The tensile strength is higher than 1200 $\mathrm{MPa}$ in the fibre direction on a temperature range varying from -50 to $250^{\circ} \mathrm{C}$. The material has also an outstanding fatigue strength under tension in this material direction. At $200^{\circ} \mathrm{C}$, the fatigue strength for a high number of cycles $\left(2.10^{6}\right)$ is still approximately $50 \%$ of the static strength. One of the weak point of this composite laminate is the relatively low interlaminar shear strength at high temperature.
\end{abstract}

Keywords: A. Polymer-matrix composites (PMCs), B. Thermomechanical, D. Mechanical testing, E. Thermoplastic resin, 


\section{INTRODUCTION}

Many industries, such as electrical, automotive, aerospace and telecommunications are looking for composite parts capable of extended performance at elevated temperatures. Effectively, in numerous structural engineering systems, the composite components are exposed to a combination of both high mechanical solicitations and thermal loadings.

High temperature thermoplastic materials are promising materials since, in addition to the classical advantages of thermoplastic polymers (recyclability, resistance to chemicals, solvents and radiation, indefinite shelf life, ability to be repair, re-melt and re-processed ...), they generally offer enhanced mechanical properties (high level of toughness, strength, stiffness and resistance to fatigue) [1-15].

Moreover they keep their physical properties at high temperatures and exhibit thermal stability even in the longer run.

The demand for heat resistance in polymers for composite applications was first motivated by military and civil aeronautical and aerospace developments in the 1960s [1]. One of the first thermoplastic (TP) polymers developed is polyphenylene sulphide (PPS) with a relatively low operating temperature (approximately $100^{\circ} \mathrm{C}$ ). Few years later the polyethersulfone (PES) and polyether ethercetone (PEEK) polymers with intermediate operating temperature of about $150^{\circ} \mathrm{C}$ were marketed. In parallel, the high temperature TP polymers based on polyimide (TPIs) were developed. The main commercial references are LARC-TPI, LARC PISO 2 , LARC RP-46 and Aurum New TPI with operating temperature up to 200$250^{\circ} \mathrm{C}$

The important difficulties encountered with such polymers concerned their process ability, the main challenge being to maintain a high glass transition temperature while retaining sufficient melting ability in the uncured state [1]. Significant efforts have been devoted to develop melt processable solutions and a high compatibility with carbon fibres. Literature reports several experimental investigations on this composite family. The main studies were performed on carbon fibre (CF) reinforced PPS, PEEK, PEI (polyetherimide) matrices [2], [3], [5], [9-12]. Fig. 1 proposes a graphical overview of the performance of such materials by plotting the tensile strength as a function of temperature.

For quasi isotropic CF/PPS composites, a relative good stability of mechanical properties was measured between ambient temperature and $120^{\circ} \mathrm{C}$, with a decrease of only approximately $3 \%$ in Young's modulus, 
$8 \%$ in strength and $5 \%$ in strain on this temperature range [2]. For quasi-isotropic AS4/PEEK submitted to tensile loading, decreases in strength of approximately $7 \%$ and $20 \%$ were measured at respectively $75^{\circ} \mathrm{C}$ and $150^{\circ} \mathrm{C}$ [3]. In the fibre direction, for UD composites, Uematsu et al. [5] observed a decrease in tensile rigidity of $7 \%$ between ambient temperature and $200^{\circ} \mathrm{C}$. Walther [12] showed a significant decrease in Young's modulus and ultimate strength only from $100^{\circ} \mathrm{C}$ for CF/PPS (UD composite), and from $150^{\circ} \mathrm{C}$ for $\mathrm{CF} / \mathrm{PEEK}$ (UD composite) with a decrease in strength of approximately $11 \%$ from the ambient temperature. Mahieux et al. [10], [11] pointed out that the number of cycles to failure of AS4/PEEK decreases when tests are performed at $150^{\circ} \mathrm{C}$ in comparison to ambient temperature. They found a stable storage modulus between ambient temperature and $100^{\circ} \mathrm{C}$ for AS4/PPS, AS4/PEI and AS4/PEEK composites.

The temperatures at which the onset of drop in mechanical properties is measured correspond generally to the glass transition of matrices.

Literature reports only a few studies dedicated to TPI [1], [4], [16], [17]. Published results show a good stability of mechanical properties up to $250^{\circ} \mathrm{C}$ and negligible weight loss up to $400^{\circ} \mathrm{C}$ [16]. These works were mainly focused on PI-SP, LARC-TPI, ULTEM and Aurum PIXA Thermoplastic Polyimide composite materials.

Literature also reports for thermoplastic composites that the manufacturing processes could induced effects, such as residuals stresses and strains, that can influence the mechanical performance of the produced material [18], [19].This might be critical for the performance characterization of complex composite parts.

In this paper, a novel high-temperature thermoplastic polyimide (Aurum PD400) composite supplied by Mitsui chemicals inc. is studied. Its thermal, rheological and mechanical properties are characterized at the scale of specimens cut in tape roll and in tubular laminates manufactured using thermocompression and heated-head thermoplastic filament winding processes. Tubular or cylindrical composite structures are effectively used in many fields of application, such as speed rotors, flywheels, pressure vessels, transportation systems etc. The accurate determination of the mechanical strength and long-term durability of these structures, when exposed to a combination of in-service loads and environments, is of great importance for the optimisation of their design reliability and mass, in particular in the transportation industry. During operation, a component's stress state is mostly multiaxial, although it is 
largely dominated by the circumferential direction. Axisymmetric, cylindrical products and structures made from composite materials are often manufactured using a filament winding process, with the reinforcement oriented mainly along the hoop axis.

\section{MATERIALS AND METHODS}

\section{$2.1 \quad$ Materials}

Single wide band (tape) of unidirectional carbon fibre reinforced polyimide composite, provided by Mitsui Chemicals Inc., was used in this study. This tape was made of T700S type of carbon fibres and high-temperature TPI matrix (Aurum PD400). The width of the tape was $13 \pm 0.5 \mathrm{~mm}$ and the thickness $0.29 \pm 0.02 \mathrm{~mm}$. The volume fraction of fibre was $50 \%$ which involved 48000 fibres in the cross-section of the tape.

\subsection{Composite specimen manufacturing and preparation}

Two types of composite structures, i.e. plate and tubes, were manufactured using respectively thermocompression and heated-head thermoplastic filament winding processes.

The plates with ten unidirectional layers $\left(\left[0^{\circ}\right]_{10}\right)$ were hot pressed at $400^{\circ} \mathrm{C}$ and under 6 bars during 1 hour. They were prepared by a simple hand lay-up method. The hot pressed plates have a width of 80 $\mathrm{mm}$, a length of $150 \mathrm{~mm}$ and a thickness of $2.5 \mathrm{~mm}$.

Tubular specimens were manufactured using the heated-head thermoplastic filament winding facility of a private company. Operations were performed on a $120 \mathrm{~mm}$ diameter, $400 \mathrm{~mm}$ long steel mandrel with a computer-controlled filament winding machine. The layers were bonded with a gaz torch (with a temperature of approximately $450^{\circ} \mathrm{C}$ at the surface of the material), and consolidated by a roller. The winding pitch was $14 \mathrm{~mm}$, which induced winding angle of $88^{\circ}\left(90^{\circ}\right.$ being a purely circumferential winding angle). Two different tubular specimens have been produced, one with 6 layers and the second with 18 layers with respectively 1.55 and $4.6 \mathrm{~mm}$ in thickness. The composite tubes were removed from their mandrels and ring-shaped specimens were produced by cutting and machining the tubes.

\subsection{Thermal characterization}

\subsubsection{Thermal degradation}

The thermal degradation was investigated under inert and oxidative environments using thermogravimetric analysis. A Thermogravimetric Analyser (TGA), SETARAM SESTYS Evolution, was 
used to identify the thermal degradation under inert environment (argon). Investigations were made while heating the samples from room temperature to $700{ }^{\circ} \mathrm{C}$ at a heating rate of $5^{\circ} \mathrm{C} / \mathrm{min}$. Three samples of 60 mg were tested.

Thermal stability and degradation was also investigated under oxidative environment as a function of time and temperature of exposure according to the Standard test method ASTM D2584-02 [20]. Tests were performed in an oven with a heating rate of $4^{\circ} \mathrm{C} / \mathrm{min}$ up to the temperature plateau. Each specimen was weighted before and after thermal exposure. Five specimens of $3.5 \mathrm{~g}$ were tested at several temperatures and times of exposure, i.e. 450,500 and $550^{\circ} \mathrm{C}$ during one hour, and 400 and $560^{\circ} \mathrm{C}$ during three hours of exposure.

\subsubsection{Coefficients of Thermal Expansion}

Coefficients of Thermal Expansion (CTE) were determined in longitudinal and transversal directions using a dilatometer SETARAM SESTYS Evolution. Three samples were tested in each direction, with a dimension of $8.5 * 5 * 2.2 \mathrm{~mm}^{3}$. The expansion of the specimen was measured using a linear variable differential transformer sensor (LVDT) with a constant load of $15 \mathrm{cN}$. Tests were realized in oxidative environment, on a range of temperature from 30 to $400^{\circ} \mathrm{C}$ with a heating rate of $2^{\circ} \mathrm{C} / \mathrm{min}$. The coefficients of thermal expansion were determined by linear regression of the strain/temperature curve between 50 to $200^{\circ} \mathrm{C}$. The glass transition temperature $\left(\mathrm{T}_{\mathrm{g}}\right)$ and the melting temperature $\left(\mathrm{T}_{\mathrm{f}}\right)$ were also determined using these curves.

\subsection{Mechanical characterisation}

\subsubsection{Tensile monotonic properties}

\section{Individual lamina}

The in-plane elastic properties of the individual lamina were determined at different temperatures on test coupons sawn in the provided rolls of single wide band of unidirectional composite.

Tensile tests in the fibre direction were performed according to the ASTM D3039-00 [21]. The length of the specimens was $250 \mathrm{~mm}$ and the cross-section area $13 * 0.29 \mathrm{~mm}^{2}$. Straight metallic end tabs were glued at each extremity of the tape coupon using Duralco 4703 adhesive after composite surface preparation (sanded and cleaned with acetone). Axial strain was measured using a laser extensometer (EIR LE05). Young's Modulus was identified by linear regression of the stress-strain curve on a strain range between 
0 and $0.4 \%$. Tests were performed using an electromechanical tensile machine (Instron 6025) with displacement control at a speed of $1 \mathrm{~mm} / \mathrm{min}$. Three to eleven specimens were tested at six temperatures comprised between -50 to $200^{\circ} \mathrm{C}$. The heating rate to reach the requested temperature was approximately $4^{\circ} \mathrm{C} / \mathrm{min}$ and a temperature plateau was hold during $30 \mathrm{~min}$ before running the test in order to obtain an homogeneous temperature inside the specimen.

Tensile tests in the transverse direction were realised using a Dynamics Mechanical Analysis (DMA) (Bose Electroforce 3200) at ambient temperature. The length of the specimens was $10 \mathrm{~mm}$ and the crosssection area $1.5^{*} 0.29 \mathrm{~mm}^{2}$. Tests were performed on 5 specimens with a displacement control at a speed of $0.3 \mathrm{~mm} / \mathrm{min}$. The apparent Young's modulus was determined by linear regression of the stress-strain curves on a range of strain comprised between 0 and $0.4 \%$.

\section{Ring shaped specimen}

The tensile strength in the fibre direction was also determined on unnotched ring-shaped specimens according to the standard ASTM D2290-00 [22] “Apparent hoop tensile strength of plastic or reinforced plastic pipe by split disk method". The ring specimens had an internal and external diameter of respectively 120 and $121.55 \mathrm{~mm}$ and a width of $12 \mathrm{~mm}$. The specimens were produced free of machining marks and each were uniform in cross-section.

The home-made test fixture used for these tests involves two half disk shaped components which were attached to one upper and one lower connecting arm with pins. Ball-and-socket joins were used to articulate the connecting arms and ensure their self-alignment. In this way, the direction of the applied pull is directly perpendicular to the split axis of the test fixture. The test fixtures were mounted on a universal testing machine (Instron 8501). The specimens were subjected to a load control, with a $0.3 \mathrm{kN} . \mathrm{s}^{-}$

${ }^{1}$ moving crosshead velocity at different temperature levels (ambient temperature, $200^{\circ} \mathrm{C}$ ). Three specimens were tested for each temperature. The ultimate hoop strength and strain were determined using the applied load and the initial cross-sectional areas of the specimen in the region of the gap between split disks. Strains were measured using bi-axial strain gages with a maximum measurement range of $2 \%$ and supplied by Vishay Measurements Company. In this test, an apparent hoop strength rather than a true hoop strength is obtained because of the bending moment appearing during the test at the split between the split disk test fixtures. 


\subsubsection{Fatigue strength}

Tension-tension fatigue tests were also performed on both individual lamina coupons sawn in tape rolls and ring-shaped specimens. The experimental configurations (loading machine, specimen shape and preparation) were similar than for monotonic tests.

The fatigue tests were performed in tension under load amplitude control mode, with a sinusoidal waveform at a frequency of $6 \mathrm{~Hz}$ and a ratio between minimum and maximum stress (R) of 0.1 for individual lamina coupons at ambient temperature and with a $\mathrm{R}$ ratio of 0.2 and a frequency of $5 \mathrm{~Hz}$ at ambient temperature and at a temperature of $200^{\circ} \mathrm{C}$ for ring-shaped specimens.

For each type of specimen, three levels of maximum stress were applied. The levels were $90 \%, 80 \%, 70 \%$ of the quasi-static tensile failure stress. At least two replicates were tested at each stress level. Tests were stopped at specimen failure or when reached $2.10^{6}$ cycles.

\subsubsection{Viscoelastic properties}

Viscoelastic properties (storage and loss moduli and loss factor) were determined in the transverse direction using a DMA Bose Electroforce 3200 on coupons sawn in the unidirectional plate. The size of the rectangular specimen was $58 * 5 * 2.5 \mathrm{~mm}^{3}$. Four specimens were tested in isothermal conditions between 30 and $275^{\circ} \mathrm{C}$ with steps every $5^{\circ} \mathrm{C}$. The temperature was stabilized during two minutes before each measurement to ensure a homogeneous temperature inside the specimen. The temperature was measured by using a thermocouple placed in a reference sample located in the heating chamber close to the tested specimen. The frequency of the sinusoidal excitation varies from 0.1 to $10 \mathrm{~Hz}$. The compliance of the test set-up was taken into account for the determination of the viscoelastic properties. A tensile harmonic load was applied on the specimens with mean amplitude of $5 \mathrm{~N}$ and peak-to-peak amplitude of $8 \mathrm{~N}$.

\subsubsection{Interlaminar fracture toughness}

Interlaminar fracture toughness was determined using the Double Cantilever Beam (DCB) and the Lauke tests.

\section{DCB test}


For mode I testing, the double cantilever beam test (DCB) was conducted according to the standard ASTM D5528-94 [23]. Delamination tests were carried out on unidirectional laminates manufactured by thermocompression. A crack starter (thin film of Teflon ${ }^{\circledR}$ material) was inserted between the $5^{\text {th }}$ and the $6^{\text {th }}$ layer. The thickness of the specimens was approximately $2.5 \mathrm{~mm}$. Cracks opening loads were applied through the piano hinges under displacement control at a speed of $1 \mathrm{~mm} / \mathrm{min}$. In order to monitor crack propagation during loading, the edges of the specimens were marked up to $70 \mathrm{~mm}$ from the tip of the insert. The marking were made at $5 \mathrm{~mm}$ intervals. Three to five specimens were tested at each temperature level (ambient, 110 and $200^{\circ} \mathrm{C}$ ). The onset of delamination was monitored until the $3 \mathrm{~mm}$ delamination length, then the specimen was unloaded. It was loaded again to monitor the mode-I precrack propagation. The load and displacement were continuously recorded and the crack length was recorded using a digital video camera.

From the measurements of load, displacement and crack length, the critical strain energy release rate, $\mathrm{G}_{1 \mathrm{C}}$ was first calculated by using the general theory of linear elastic fracture mechanics [23] :

$G_{1 C}=-\frac{\partial E_{E}}{\partial A}=\frac{1}{2 b} P^{2} \frac{\partial C}{\partial a}$

Where $P$ is the critical load, $b$ the width of the specimen, $C$ is the compliance and $a$ the crack length. Data were also reduced using the Modified Compliance Calibration (MCC) method presented in the ASTM D5528-94 [23] for which the compliance relationship is found from a least squares plot of the delamination length normalized by specimen thickness versus the cube root of the corresponding compliance. So $\mathrm{G}_{1 \mathrm{C}}$ is expressed following this formula the formula:

$G_{1 C}=\frac{3 m}{2(2 e)}\left(\frac{P}{b}\right)^{2}\left(\frac{b C}{N}\right)^{2 / 3} F$

Where $e$ is the thickness, $F$ and $N$ are correction coefficients for respectively the large displacement effects and the stiffening of the specimen by the blocks, $m$ is the coefficient determined by the ratio $(b C / N)^{1 / 3}$ and the length of delamination $a / 2 e$ as illustrated in Fig. 2.

For determining the $\mathrm{G}_{1 \mathrm{C}}$ values at crack initiation $\left(G_{I C}^{i n i}\right), 3$ methods were used according to the standard D5528 [23], i.e. the VIS point at $3 \mathrm{~mm}$ of pre-crack, the 5\% Max point and the NL (Non Linearity) point. The determination of the energy release at crack initiation is effectively challenging. The VIS point was determined during the test by optical observation. The Non Linearity (NL) and 5\% Max points were determined by post-treating the load/displacement curve. The point of deviation from linearity (NL point) 
was determined by drawing a straight line from the origin ignoring any initial deviations. As underlined by Brunner et al. [24], it may be difficult to reproducibly determine the position of this point on the load/displacement curve. So, we also propose in this work to determine the NL point using AE data as suggested by Albertsen et al. [25].

For propagation, the values of the critical strain energy release rate $\left(G_{I c}^{\text {prop }}\right)$ were computed using points pick up every $5 \mathrm{~mm}$ from the pre-crack position.

\section{Lauke test}

The method designed by Lauke et al. [24-26] was used to assess the delamination properties of composite rings fabricated by winding process. These interlaminar shear tests were carried out on curved sample (quarter pieces) cut with diamond saw in a pipe measuring $300 \mathrm{~mm}$ in length, $120 \mathrm{~mm}$ in internal diameter and $4.65 \mathrm{~mm}$ in thickness. Tests were performed on a hydraulic machine (Instron 8501) at different temperature levels $\left(23,100\right.$ and $\left.200^{\circ} \mathrm{C}\right)$. As proposed by Lauke et al. [28], our home-made testing set-up consists of one rigid curved supporting jig and another that can be loaded by the testing machine (Fig. 3). The supporting jigs ensure that during loading, mainly shear forces are acting in the midplane of the curved sample. The loading direction coincides with the orientation of the fibres in the hoop wound specimen segments. The dimensions of the specimen are $4.65 \mathrm{~mm}$ in thickness, $10 \mathrm{~mm}$ in height $(h)$ and $15 \mathrm{~mm}$ in width $(w)$. The samples dimensions are determined in order to obtain a lever perpendicular to the direction of loading.

From the force measurement the interlaminar shear strength is easily obtained as followed :

$$
\tau=\frac{\left(l_{k} / l_{s}\right) F}{w h}
$$

Where $F$ is the maximum applied load, $l_{k}, l_{s}$, the levers of the test device.

The shear strength values determined represent the average of at least four samples of one temperature test. A cross head displacement of $1 \mathrm{~mm} / \mathrm{min}$ was used.

\subsection{Acoustic emission}

To record acoustic emissions during DCB tests, a data acquisition system from the EPA (Euro Physical Acoustics, MISTRAS Group) corporation was used. A miniature piezoelectric sensor ( $\mu-80)$ was used 
with a resonance frequency ranging from $250-325 \mathrm{kHz}$, a preamplifier with a gain of $40 \mathrm{~dB}$, a 20-1000

$\mathrm{kHz}$ filter, a PCI card with a $5 \mathrm{MHz}$ sampling rate, and AEWin software for real-time feature extraction. The calibration of the system was performed after installation of the transducers on the specimen and before each test using a pencil-lead break (PLB) procedure. The sensor was positioned on the top surface of the specimen. The acoustic emission signals were detected and extracted in the stream using the threshold-based detection technique developed by EPA. It is based on three acquisition parameters called PDT $($ Peak Definition Time $=60 \mu \mathrm{s})$, HDT $($ Hit Definition Time $=120 \mu \mathrm{s})$ and HLT $($ Hit Lock Time $=$ $300 \mu$ s) identified using preliminary measurements, and in particular PLB without loading. A part of the ambient noise was filtered using a threshold of $40 \mathrm{~dB}$.

\section{Results and discussion.}

\subsection{Thermal properties}

Typical curves of thermal expansion in longitudinal and transversal directions are presented in Fig. 4. The CTE were determined from these curves using a linear regression between ambient temperature and $200^{\circ} \mathrm{C}$. In the fibre direction the mean value of the coefficient of thermal expansion is $-1.710^{-6} /{ }^{\circ} \mathrm{K}$. This result is in agreement with data published by Walsh and Adams [29]. In the transverse direction, the mean value of CTE is $3010^{-6} /{ }^{\circ} \mathrm{K}$. These results clearly emphasise the high anisotropy of CTE for such a material.

Above $200^{\circ} \mathrm{C}$, the evolution of the expansion as a function of temperature is non-linear and two transition temperatures can be observed, the first one at approximately $235^{\circ} \mathrm{C}$ and the second one at $385^{\circ} \mathrm{C}$. These transition temperatures were attributed to the glass transition temperature $\left(\mathrm{T}_{\mathrm{g}}\right)$ and the melting temperature $\left(\mathrm{T}_{\mathrm{f}}\right)$ of the polymeric material. This latest is specifically interesting to optimize the manufacturing process (i.e. the optimal temperature of the flame of the heated-head of the filament winding machine). These values are in agreement with the datasheet of the manufacturer and also with the work of Haixia et al. [17] related to a semi-crystalline Aurum® thermoplastic Polyimide (TPI), with a Tg of approximately $250^{\circ} \mathrm{C}$ and a $\mathrm{T}_{\mathrm{f}}$ of $380^{\circ} \mathrm{C}$. Tg was also determined using DMA at different frequencies (Fig. 5). Results confirm the outstanding high value determined with dilatometry. From the peak of loss modulus (Fig.5), and for a loading frequency of $0.1 \mathrm{~Hz}$, the value of Tg is detected at approximately $255^{\circ} \mathrm{C}$. A Tg equal to $255^{\circ} \mathrm{C}$ was also measured by Gamstedt and Berglund [6] on TPI based material. 
An increase of about $7^{\circ} \mathrm{C}$ in $\mathrm{Tg}$ was measured when the loading frequency was increased of a decade from 0.1 to $10 \mathrm{~Hz}$. The dependence of $\mathrm{Tg}$ to the frequency is usual for such polymeric materials [30]. The difference in Tg observed when using dilatometry or DMA techniques can be attributed to the difference in the solicitation frequency. DMA is generally considered as a more accurate method for such a determination than dilatometry or DSC [30].

Figure 6 presents the evolution of the weight loss of the composite material as a function of temperature for different times of exposure and in different environments. As it can be observed on this figure, the weight loss is strongly dependent on the environmental conditions. In inert atmosphere, the weight loss starts to be significant above $500^{\circ} \mathrm{C}$ (Fig. 6a). As observed by Haixia and Ratta [17], [16], a weight loss of $5 \%$ is reached at a temperature of $530{ }^{\circ} \mathrm{C}$.

In oxidizing atmosphere, the onset of thermal degradation is shifted to lower temperature, approximately $400^{\circ} \mathrm{C}$ (Fig. 6b). In such conditions, the weight loss is of approximately $3 \%$ after one hour of exposure at $450^{\circ} \mathrm{C}$

These results clearly illustrate the high temperature resistance of such thermoplastic polyimide material and its ability to be processed up to temperature of $400^{\circ} \mathrm{C}-450^{\circ} \mathrm{C}$ (at least considering short times of exposure).

\subsection{Influence of temperature on the mechanical properties}

\subsubsection{Tensile properties}

\section{Transverse direction}

The monotonic tensile properties determined in the transverse direction are listed in Tab. 1. The mean value of the Young's modulus is $1.9 \mathrm{GPa} \pm 0.2 \mathrm{GPa}$. This value is very low compared to the $5 \mathrm{GPa}$ specified by the supplier for the raw polymer and to the $7.3 \mathrm{GPa}$ determined by Kawai et al, on $\mathrm{CF} /$ composite at $100^{\circ} \mathrm{C}$. It can be noticed that the small size of specimen does not allow us to carry out a normalised test.

Table 1. Mechanical properties determined in the transverse direction on the individual lamina, Mean value \pm standard deviation (Coefficient of variation).

$$
\text { Young Modulus Strain to rupture Stress to rupture }
$$
(GPa)
$(\%)$
$(\mathrm{MPa})$ 


\begin{tabular}{cccc}
\hline This work & $1.9 \pm 0.2$ & $0.9 \pm 0.25$ & $15 \pm 2.5$ \\
& $(0.105)$ & $(0.27)$ & $(0.16)$ \\
Literature [4], [6] & $3-7.3$ & - & $25.3-90$
\end{tabular}

The influence of temperature on the transverse rigidity of the composite has been investigated using DMA on laminates. Fig.7 shows the evolution of the storage modulus as a function of temperature for the 3 tested frequencies of solicitation. The storage modulus, of approximately $2.3 \mathrm{GPa}$ is reasonably constant on a temperature range comprised between 30 to $240^{\circ} \mathrm{C}$ and starts to decrease when the glass transition region is reached, i.e. above $250^{\circ} \mathrm{C}$. In this region (from $250^{\circ} \mathrm{C}$ to $270^{\circ} \mathrm{C}$ ), the rigidity drops significantly to reach a value of approximately $1 \mathrm{GPa}$ at $270^{\circ} \mathrm{C}$. These results emphasise and confirm the hightemperature stability of this polyimide polymer.

DMA results also showed a slight variation in E' and E', values around $120^{\circ} \mathrm{C}$. This small transition was attributed to the softening of the sizing material (epoxy-based system).

For laminate and tape the mean value of Young's modulus was approximately the same.

The mean strain at failure and strength at ambient temperature were also determined in transverse direction using monotonic tests. The mean values, respectively $0.9 \%$ and $15 \mathrm{MPa}$, are very low compared to the ones measured by Gamstedt and Berglund [6] (90 MPa on neat resin) and Kawai et al. [4] (25.3 $\mathrm{MPa}$ on $\mathrm{T} 800 \mathrm{H} / \mathrm{PI}$ ) for the same matrix. This difference for tensile strength and failure mode can be attributed to a poor adhesion between fibres and matrix at the scale of tape coupons. Indeed a premature failure of coupons can occur, in particular when compared to the expected value of $90 \mathrm{MPa}$ corresponding to the tensile strength of a virgin thermoplastic polyimide [6]. This underestimation of the strength could also be attributed to the testing conditions, and particularly to the dimensions of the coupon which do not respect the ratio between the length and the area of specimen, clamping ....

So considering uncertainties on such measurements, in particular due to the unfortunate or unsuitable experimental configuration imposed by the small width of the tape, the influence of temperature on the strength and strain at failure has not been investigated in this study.

\section{Fibre direction}


Tape specimens. The monotonic tensile properties of the T700S/Polyimide composite tape in the fibre direction are listed in Tab. 2 when exposed at different temperature levels. The average Young's modulus is approximately $110 \mathrm{GPa}$ at ambient temperature.

Table 2. Mechanical properties in the longitudinal direction for individual lamina and in hoop direction for ring-shaped specimens.

\begin{tabular}{|c|c|c|c|c|c|c|}
\hline Temperature & $\begin{array}{l}\text { Specimen } \\
\text { geometry }\end{array}$ & $\begin{array}{c}\text { Specimen } \\
\text { number }\end{array}$ & $\begin{array}{l}\text { Young } \\
\text { modulus } \\
(\mathrm{GPa})\end{array}$ & $\begin{array}{l}\text { Strain to } \\
\text { rupture }\end{array}$ & $\begin{array}{c}\sigma_{l}^{\text {rupt }} \\
(\mathrm{MPa}) \\
(\mathrm{COV})\end{array}$ & $\begin{array}{c}\text { Type of rupture } \\
\text { cascade/brush } \\
(\%)\end{array}$ \\
\hline$-50{ }^{\circ} \mathrm{C}$ & Tape & 3 & $\mathrm{nc}$ & $\mathrm{nc}$ & $1340 \pm 155(0.11)$ & $100 / 0$ \\
\hline$-20^{\circ} \mathrm{C}$ & Tape & 3 & $\mathrm{nc}$ & $\mathrm{nc}$ & $1670 \pm 530(0.32)$ & $100 / 0$ \\
\hline $23^{\circ} \mathrm{C}$ & Tape & 11 & $110 \pm 6$ & $1.7 \pm 0.15$ & $1890 \pm 285(0.15)$ & $25 / 75$ \\
\hline $110^{\circ} \mathrm{C}$ & Tape & 8 & $\mathrm{nc}$ & $\mathrm{nc}$ & $1500 \pm 300(0.2)$ & $100 / 0$ \\
\hline $200{ }^{\circ} \mathrm{C}$ & Tape & 6 & $\mathrm{nc}$ & $\mathrm{nc}$ & $1730 \pm 320(0.18)$ & $67 / 33$ \\
\hline $250^{\circ} \mathrm{C}$ & Tape & 3 & nc & nc & $1280 \pm 62(0.05)$ & $100 / 0$ \\
\hline $23^{\circ} \mathrm{C}$ & Ring & 3 & $\mathrm{nc}$ & $\mathrm{nc}$ & $1460 \pm 100(0.07)$ & $\mathrm{nc}$ \\
\hline $200^{\circ} \mathrm{C}$ & Ring & 3 & $\mathrm{nc}$ & $\mathrm{nc}$ & $1350 \pm 120(0.09)$ & $\mathrm{nc}$ \\
\hline
\end{tabular}

The stress/strain curve of the individual lamina tensile tested in the fibre direction at the scale of tape coupons is plotted in Fig. 8b. The material exhibits purely elastic-brittle behaviour. Its mean tensile strength is $1890 \mathrm{MPa}$. This order of magnitude is in agreement with data of literature collected for carbon fibre reinforced high-temperature thermoplastics [1], [3], [4], [7], [12]-[15]. The mean strain at failure is $1.7 \pm 0.15 \%$

Two types of failure were observed for this material at ambient temperature. The largest proportion of tested specimens (75\%) had a brush-like failure (see Fig. 8 (a)). This type of failure is generally due to a poor fibre-matrix adhesion [6-8], [12], [29-32], which results in fibre/matrix debonding and splitting. In such failure mode, broken fibres are dispersed at any place along the specimen. The second type of failure was cascade-like failure (see fig. 8 (a)). This one is generally observed in UD composites when a better or stronger adhesion between fibre and matrix is achieved. The imposed load induces a breakage in fibres which have the lowest strength. From this point of local failure, different damages can appear, such as 
longitudinal and transversal matrix cracks and fibre/matrix debonding. The strong interface between fibres and matrix brings about the transverse matrix crack. As the transversal crack growths, the local load is transferred on the adjacent fibres that break alternately until the total failure of the specimen. This type of rupture is generally observed with few or no splitting.

At ambient temperature, the presence of these two types of breakage was attributed to an heterogeneity in the quality of the adhesion between fibres and matrix, probably related to the sizing and tape manufacturing processes [6]. For such composite material, sizing is a crucial step since carbon fibres have naturally a poor adhesion with thermoplastic polyimide matrix. The thin layer of the epoxy-based sizing system can be easily observed on the SEM picture proposed in Fig. 9. This figure shows the fractography of a tape. The smooth layer of the sizing matter has a thickness of approximately $500 \mathrm{~nm}$. Tests were also performed at different temperature levels comprised between $-50^{\circ} \mathrm{C}$ and $250^{\circ} \mathrm{C}$. Results are synthetized in Tab. 2. A slight decrease in the mean strength, approximately $8 \%$, is observed at $200^{\circ} \mathrm{C}$. More surprisingly, a drop in strength (approximately $20 \%$ ) was observed at the particular temperature of $110^{\circ} \mathrm{C}$. Only cascade-like failure were observed at this temperature, contrary to other temperatures $\left(23^{\circ} \mathrm{C}\right.$ and $\left.200^{\circ} \mathrm{C}\right)$ at which both failure modes were recorded. This located decrease in strength is suggested to be related to the softening temperature of the sizing matter. At the glass transition temperature, the softening of this thin layer may modify the load transfer between fibres and matrix resulting in a change in failure mode. This phenomenon was also observed by Walther [12] (with also epoxy-based and polyurethane sizing agents) on UD composites that were tested at ambient temperature and $140^{\circ} \mathrm{C}$. Walther [12] shows a cascade-like failure at $140^{\circ} \mathrm{C}$ and a brush-like failure at $35^{\circ} \mathrm{C}$ for a vinyl ester specimen with epoxy fiber-matrix interface.

Near the glass transition temperature of the polyimidide matrix (i.e. $250^{\circ} \mathrm{C}$ ), the mean strength was also significantly deteriorated with a decrease of $33 \%$, Tenney et al; [1] pointed out a decrease of $35 \%$ in flexural strength for a LARC ${ }^{\circledR}$ PETI-4 between 23 and $177^{\circ} \mathrm{C}$. Again, at this temperature, all specimens had a cascade-like failure appearance.

For temperatures below $0^{\circ} \mathrm{C}$, a decrease in strength of 11 and $30 \%$ was respectively observed at $-20^{\circ} \mathrm{C}$ and $-50^{\circ} \mathrm{C}$. At these temperatures, all specimens have a cascade-like failure. This could be due to the brittle fracture behaviour of matrix in cold atmosphere. This result can be correlated to the work of 
Franco et al. [35] who showed that the fatigue resistance is $30 \%$ higher at ambient than at negative temperature $\left(-55^{\circ} \mathrm{C}\right)$ for PPS matrix.

Excepted for $-20^{\circ} \mathrm{C}$, the $\mathrm{CoV}$ is approximately the same; at the tape scale, this composite has an important strength over a large range of temperature.

Ring-shaped specimens. Tensile strength in the fibre direction was also determined at the scale of ringshaped specimens. The mean value of the hoop strength is approximately $1460 \mathrm{MPa}$. This strength is lower than for individual lamina. This can be attributed to:

(i) Fibre orientation

In ring-shaped specimen, fibres are not oriented in the circumferential direction, the winding angle is estimated to be approximately $\pm 2^{\circ}$. This stacking sequence could result in additional damage modes (when compared to tensile tests performed at the scale of tape specimens), such as inter-layers delamination.

(ii) Internal stresses

During manufacturing process, the tape was tensioned on the mandrel. This induces a significant pre-stress (approximately $400 \mathrm{MPa}$ ) in the composite material that can have an effect on the apparent hoop tensile stress measured during the test.

(iii) Stress heterogeneity and multi-axiality In tensile tests on ring specimens, the bending moment (at the gap between the half cylinders) induces an heterogeneous and multi-axial stress state in the rings [27], [34-37], that can decrease the apparent hoop strength.

(iv) Scale and geometrical effects.

This effects can also induce a change in damages sequences and thus in the apparent strength.

At $200^{\circ} \mathrm{C}$, a slight decrease in strength is observed, approximately $8 \%$ when compared at ambient temperature (ie $1350 \mathrm{MPa}$ vs. $1460 \mathrm{MPa}$ ). This order of magnitude is in accordance with the result obtains on the individual lamina. 


\subsubsection{Fatigue behaviour}

S-N curves for tensile-tensile fatigue tests on tape and ring-shaped specimens are given in Fig. 10. Results show that both types of specimens present a gradual decline in fatigue strength with increasing number of fatigue cycles. For a given loading level, some dispersion in fatigue lifetime can be observed. This scattering is particularly significant for ring-shaped specimens. The fatigue strength as a function of number of cycles can be fitted by the Wöhler law.

The fatigue strength for a high number of cycles ( 2 millions) is approximatively $1390 \mathrm{MPa}$ for tape specimens, approximately $65 \%$ of the monotonic tensile strength. This limit is slightly higher than the one mentioned by Kawai et al. [4] for a T800H/Polyimide laminate and Diao et al. [4], [13] for a CF/PEEK laminate, and in agreement with the work of Franco et al. [35] and De Baere et al. [40] for CF/PPS composite. In such testing conditions (fatigue test at ambient temperature on tape specimens), a brush-like failure was observed for all tested specimens.

For ring-shaped specimens the fatigue life is slightly lower than for the tape. The fatigue strength for 2 million of cycles is $850 \mathrm{MPa}$, approximately $60 \%$ of the monotonic tensile strength at ambient temperature and $570 \mathrm{MPa}$ at $200^{\circ} \mathrm{C}$ approximately $40 \%$ of the monotonic tensile strength at $200^{\circ} \mathrm{C}$. Results point out the outstanding fatigue strength of such composite laminate at high temperature.

\subsubsection{Interlaminar strength}

The interlaminar strength was evaluated by two methods: the Lauke test and the DCB test at the level of curved and plate specimens respectively.

The shear strength of curved sample cut in composite rings is approximately $28 \mathrm{MPa}$ at $23^{\circ} \mathrm{C}$ (see Tab. 3). Such composite has a relatively high shear strength when compared to the 15 MPa measured by Henninger [27] on glass fibre-Polypropylene and glass fibre-Polyamide12 composites using the Lauke test. On the contrary, this value is significantly lower than the shear strength measured at $59 \mathrm{MPa}$ by Kawai et al. [4] on plate specimens of $\mathrm{T} 800 \mathrm{H} /$ Polyimide (with a fibre orientation of $10^{\circ}$ ). It was previously underlined [27] that the Lauke test gives lower values of shear strength than the ones that can be determined using torsion test on tubular specimens or tests on plate specimens.

A decrease in shear strength is observed with increasing temperature. It reaches a value of $11.5 \mathrm{MPa}$ at $200^{\circ} \mathrm{C}$ (approximately $60 \%$ of the strength at ambient temperature). This decrease is attributed to the 
degradation of the adhesion between layers inside the laminate when approaching the glass transition temperature of the matrix [41].

Table 3. Energy release rates at crack initiation and propagation determined using DCB tests, and interlaminar shear strength determined using Lauke tests, as a function of temperature.

\begin{tabular}{|c|c|c|c|c|c|c|}
\hline & $\begin{array}{l}\mathrm{G}_{1 \mathrm{C}} \mathrm{ini}(\mathrm{NL}) \\
\left(\mathrm{KJ} \cdot \mathrm{m}^{-2}\right)\end{array}$ & $\begin{array}{l}\mathrm{G}_{1 \mathrm{C}} \mathrm{ini}(\mathrm{NL}) \\
(\mathrm{AE} \text { method) } \\
\left(\mathrm{KJ} . \mathrm{m}^{-2}\right)\end{array}$ & $\begin{array}{l}\mathrm{G}_{1 \mathrm{C}} \text { ini }(\mathrm{VIS}) \\
\left(\mathrm{KJ} \cdot \mathrm{m}^{-2}\right)\end{array}$ & $\begin{array}{l}\mathrm{G}_{1 \mathrm{C}} \text { ini }(\mathrm{Max}) \\
\left(\mathrm{KJ} \cdot \mathrm{m}^{-2}\right)\end{array}$ & $\begin{array}{l}\mathrm{G}_{1 \mathrm{C}}{ }^{\text {prop }} \\
\left(\mathrm{KJ} \cdot \mathrm{m}^{-2}\right)\end{array}$ & $\begin{array}{l}\text { Ultimate } \sigma_{\mathrm{z} \theta} \\
(\mathrm{MPa})\end{array}$ \\
\hline $23^{\circ} \mathrm{C}$ & $0.86 \pm 0.06$ & $0.78 \pm 0.06$ & $0.965 \pm 0.06$ & $1.13 \pm 0.013$ & $0.81 \pm 0.085$ & $28 \pm 4.2$ \\
\hline $110^{\circ} \mathrm{C}$ & $\mathrm{Nc}$ & $\mathrm{Nc}$ & $0.12 \pm 0.04$ & $0.25 \pm 0.054$ & $0.362 \pm 0.07$ & $19.5 \pm 3.5$ \\
\hline $200^{\circ} \mathrm{C}$ & $\mathrm{Nc}$ & $\mathrm{Nc}$ & $0.115 \pm 0.03$ & $0.21 \pm 0.09$ & $0.32 \pm 0.11$ & $11.2 \pm 3.4$ \\
\hline
\end{tabular}

Table 3 summarises the values of energy release rates measured at crack initiation and propagation using the $\mathrm{DCB}$ test. The three values of $\mathrm{G}_{1 \mathrm{C}}$ at crack initiation are given. At ambient temperature, the average

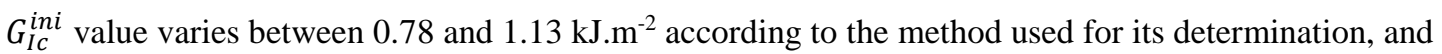
the energy release at crack propagation is approximately $0.81 \mathrm{~kJ} . \mathrm{m}^{-2}$. This difference in energy release rate between crack initiation and propagation can be attributed to a contrast between matrix-based and composite-based failure behaviour. The crack starter area is generally a matrix rich region. So, crack initiation could be mainly driven by matrix behaviour, while its propagation could be more dependent to the composite material behaviour. The matrix being ductile at ambient temperature, a matrix-based failure behaviour may result in an increase in $G_{I c}^{i n i}$.

As for of curved specimens, interlaminar strength of plate laminates (including both $G_{I c}^{i n i}$ and $G_{I c}^{\text {prop }}$ values) decreases with increasing temperature. For $G_{I c}^{\text {ini }}$, a strong decrease of about $80 \%$ between ambient temperature and $200^{\circ} \mathrm{C}$ is observed. This was also observed by Kim and Ye [42], who noticed a modification in matrix ductility that can potentially induce a decrease in $G_{I c}^{i n i}$ value in the rich matrix region. Results also show that $G_{I c}^{\text {prop }}$ decreases of about $55 \%$ between $23^{\circ} \mathrm{C}$ and $200^{\circ} \mathrm{C}$.

As an unexpected result, the energy release is higher for crack propagation than for crack initiation (whatever the method used to determine the energy release at crack initiation) at these temperatures $\left(110^{\circ} \mathrm{C}\right.$ and $\left.200^{\circ} \mathrm{C}\right)$. This phenomenon was attributed to necking and fibre bridging [40 - 41] (see, Fig. 11), which tend to increase the energy needed to propagate the crack. 


\section{CONCLUSIONS}

Significant improvements have been made both in the development of high temperature thermoplastic composites and of automated heated-head tow and tape placement technology for the fabrication of highperformance composites structures.

This paper highlights the high thermal resistance and the good stability in monotonic and fatigue properties up to $200^{\circ} \mathrm{C}$ that can be achieve at the scale of tubular structures manufactured using a heatedhead thermoplastic filament winding process.

The results open promising alternatives not only to thermoset-based composites but also to metallic materials used in rotating structural engineering systems where the components are exposed to a combination of both high mechanical solicitations and thermal exposition. Results show an outstanding stability in mechanical properties on a temperature range varying between $-50^{\circ} \mathrm{C}$ and $200^{\circ} \mathrm{C}$, except for the interlaminar shear strength. A significant decrease in this property was observed with increasing temperature. This could certainly be improved by an optimisation of the heated-head tape placement technology. A slight drop in tensile properties was also observed at $110^{\circ} \mathrm{C}$. This was attributed to the glass transition of the epoxy-based sizing agent.

\section{Acknowledgements}

This work is financially supported by ALSTOM Company. The authors thank to Benali BOUALEM and Gerard TRIPOT for their material expertise, and Camille GARCIN, Jean-Marc COTE and Christine Millot from FEMTO-ST institute for their skilful technical assistance respectively in material testing, mechanical devices design and MEB support. 


\section{Bibliography}

[1] D. R. Tenney, J. G. Davis, R. Byron Pipes, N. J. Johnston, et J. F. Mc Guire, « High-Temperature Polymer Technology Developed at NASA Langley », in Structural Framework for Flight: NASA's Role in Development of Advanced Composite Materials for Aircraft and Space Structures, 2011, p. 228-310.

[2] B. Vieille et L. Taleb, « About the influence of temperature and matrix ductility on the behavior of carbon woven-ply PPS or epoxy laminates: notched and unnotched laminates », Compos. Sci. Technol., vol. 71, p. 998-1007, 2011.

[3] M. H. R. Jen, Y. C. Tseng, H. K. Kung, et J. C. Huang, « Fatigue response of APC-2 composite laminates at elevated temperatures », Compos. Part B Eng., vol. 39, n 7-8, p. 1142-1146, 2008.

[4] M. Kawai, S. Yajima, A. Hachinohe, et Y. Kawase, « High-temperature off-axis fatigue behaviour of unidirectional carbon-fibre-reinforced composites with different resin matrices », Compos. Sci. Technol., vol. 61, nº 9, p. 1285-1302, 2001.

[5] Y. Uematsu, T. Kitamura, et R. Ohtani, « Delamination behavior of a carbon-fiber-reinforced thermoplastic polymer at high temperatures », Compos. Sci. Technol., vol. 53, n 3, p. 333-341, 1995.

[6] E. K. Gamstedt et L. A. Berglund, «Fatigue of thermoplastic composites », in Fatigue in composite, Woodhead., Cambridge: B. Harris, 2003, p. 314-338.

[7] E. K. Gamstedt et R. Talreja, « Fatigue damage mechanisms in unidirectional carbon-fibrereinforced plastics », J. Mater. Sci., vol. 34, n 11, p. 2535-2546, 1999.

[8] B. Harris, «A historical review of the fatigue behaviour of fibre-reinforced plastics », in Fatigue in composite, Woodhead., Cambridge: B. Harris, 2003, p. 3-35.

[9] B. Vieille, J. Aucher, et L. Taleb, «Influence of temperature on the behavior of carbon fiber fabrics reinforced PPS laminates », Mater. Sci. Eng. A, vol. 517, n 1-2, p. 51-60, 2009.

[10] C. A. Mahieux et C. Scheurer, «Elevated temperature bending stress rupture behavior AS4/APC-2 and comparison with AS4/PPS literature data », Compos. Part Appl. Sci. Manuf., vol. 33, n 7, p. 935-938, 2002.

[11] C. A. Mahieux, D. Lehmann, et A. DesLigneris, « Experimental determination of the effects of industrial oil immersion on polymer-based composites », Polym. Test., vol. 21, n 7, p. 751-756, 2002.

[12] B. M. Walther, « An Investigation of the Tensile Strength and Stiffness of Unidirectional PolymerMatrix, Carbon-Fiber Composites under the Influence of Elevated Temperatures », 1998.

[13] X. Diao, L. Ye, et Y.-W. Mai, « Fatigue behaviour of CF/PEEK composite laminates made from commingled prepreg. Part 1 experimental studies », Compos. Part A, vol. 28 A, p. 739-747, 1997.

[14] M. H. R. Jen et C. H. Lee, « Strength and life in thermoplastic composite laminates under static and fatigue loads. Part I: Experimental », Int. J. Fatigue, vol. 20, nº 9, p. 605-615, 1998.

[15] Z. Maekawa, H. Hamada, K. Lee, et T. Kitagawa, « Reliability evaluation of mechanical properties of AS4/PEEK composites », Composites, vol. 25, n 1, p. 37-45, 1994.

[16] V. Ratta, «Crystallization, morphology, thermal stability and adhesive properties of novel high performance semicrystalline polyimides », Virginia Polytechnic Institute and State University, 1999.

[17] Haixia Yang, Jingang Liu, Mian Ji, et Shiyong Yang, Novel Thermoplastic Polyimide Composite Materials. INTECH Open Access Publisher, 2012.

[18] I. Baran, K. Cinar, N. Ersoy, R. Akkerman, et J. H. Hattel, « A Review on the Mechanical Modeling of Composite Manufacturing Processes », Arch. Comput. Methods Eng., p. 1-31, 2016.

[19] P. P. Parlevliet, H. E. N. Bersee, et A. Beukers, « Residual stresses in thermoplastic composites-a study of the literature. Part III: Effects of thermal residual stresses », Compos. Part Appl. Sci. Manuf., vol. 38, n 6, p. 1581-1596, 2007.

[20] ASTM D2584-02, Standard Test Method for Ignition Loss of Cured Reinforced Resin. 2002.

[21] ASTM D3039-00, Standard test method for tensile properties of polymer matrix composite materials. 2000.

[22] ASTM D2290-00, Standard test method for apparent hoop tensile strength of plastic or reinforced plastic pipe by split disk method. 2000.

[23] ASTM D5528-94, Standard Test Method for Mode I Interlaminar Fracture Toughness of Unidirectional Fiber-Reinforced Polymer Matrix Composite. 1994. 
[24] A. J. Brunner, B. R. K. Blackman, et P. Davies, « Mode I delamination », in European Structural Integrity Society, vol. Volume 28, A. P. and J. G. W. D.R. Moore, Éd. Elsevier, 2001, p. 277-305.

[25] H. Albertsen, J. Ivens, P. Peters, M. Wevers, et I. Verpoest, « Interlaminar fracture toughness of CFRP influenced by fibre surface treatment: Part 1. Experimental results », Compos. Sci. Technol., vol. 54, no 2, p. 133-145, 1995.

[26] F. Henninger et K. Friedrich, « Thermoplastic filament winding with online-impregnation. Part A: process technology and operating efficiency », Compos. Part Appl. Sci. Manuf., vol. 33, n 11, p. 1479-1486, 2002.

[27] F. Henninger, J. Hoffmann, et K. Friedrich, « Thermoplastic filament winding with onlineimpregnation. Part B. Experimental study of processing parameters », Compos. Part Appl. Sci. Manuf., vol. 33, nº 12, p. 1677-1688, 2002.

[28] B. Lauke, W. Beckert, et K. Schneider, « Interlaminar shear strength evaluation of curved composite samples », Appl. Compos. Mater., vol. 1, p. 267-271, 1994.

[29] E. J. Walsh et D. O. Adams, « Development and Evaluation of the Quadrant Ring Test Method », Exp. Mech., vol. 48, n 3, p. 319-326, 2007.

[30] K. P. Menard, Dynamic mechanical analysis: a practical introduction. Boca Raton, Fla.: CRC Press, 2008.

[31] P. W. J. Van den Heuvel, Y. J. W. Van der Bruggen, et T. Peijs, « Failure phenomena in multi-fibre model composites : Part 1 . An experimental investigation into the influence of fibre spacing and fibre-matrix adhesion », Compos. Part A, vol. 27, p. 855-859, 1996.

[32] P. W. J. Van den Heuvel, S. Goutianos, R. J. Young, et T. Peijs, « Failure phenomena in fibrereinforced composites. Part 6: a finite element study of stress concentrations in unidirectional carbon fibre-reinforced epoxy composites », Compos. Sci. Technol., vol. 64, n 5, p. 645-656, 2004.

[33] G. A. Holmes et W. G. McDonough, « E-Glass/DGEBA/m-PDA Model Composites: Time Dependent Failure in a Brittle Multi-Fiber Composite », in INTERNATIONAL SAMPE SYMPOSIUM AND EXHIBITION, 2002, p. 1690-1702.

[34] Y. Swolfs, R. M. McMeeking, I. Verpoest, et L. Gorbatikh, « Matrix cracks around fibre breaks and their effect on stress redistribution and failure development in unidirectional composites », Compos. Sci. Technol., vol. 108, nº 0, p. 16-22, 2015.

[35] L. A. L. Franco, M. L. A. Graça, et F. S. Silva, « Fractography analysis and fatigue of thermoplastic composite laminates at different environmental conditions », Mater. Sci. Eng. A, vol. $488, n^{\circ} 1-2$, p. 505-513, 2008.

[36] B.-K. Bae, S.-K. Cho, et C.-S. Seok, « A study on ring tensile specimens », 14th Int. Conf. Strength Mater., vol. 483-484, $\mathrm{n}^{\circ}$ 0, p. 248-250, 2008.

[37] C. Kaynak, E. Salim Erdiller, L. Parnas, et F. Senel, « Use of split-disk tests for the process parameters of filament wound epoxy composite tubes », Polym. Test., vol. 24, nº 5, p. 648-655, 2005.

[38] F. Nagase, T. Sugiyama, et T. Fuketa, « Optimized Ring Tensile Test Method and Hydrogen Effect on Mechanical Properties of Zircaloy Cladding in Hoop Direction », J. Nucl. Sci. Technol., vol. 46, $\mathrm{n}^{\mathrm{o}}$ 6, p. 545-552, 2009.

[39] T. Naruse, T. Hattori, H. Miura, et K. Takahashi, « Evaluation of thermal degradation of unidirectional CFRP rings », Des. Manuf. Compos. Struct., vol. 52, n 3-4, p. 533-538, 2001.

[40] I. De Baere, W. Van Paepegem, C. Hochard, et J. Degrieck, « On the tension-tension fatigue behaviour of a carbon reinforced thermoplastic part II: Evaluation of a dumbbell-shaped specimen », Polym. Test., vol. 30, p. 663-672, 2011.

[41] W. Albouy et B. Vieille, «Determination of the damage threshold in woven-ply thermoplastic laminates at T > Tg: Acoustic emission and microscopic damage analysis », Compos. Part B Eng., vol. 64, $n^{\circ}$ 0, p. 138-146, 2014.

[42] K. Y. Kim et L. Ye, « Interlaminar fracture toughness of CF/PEI composites at elevated temperatures: roles of matrix toughness and fibre/matrix adhesion », Compos. Part Appl. Sci. Manuf., vol. 35, nº 4, p. 477-487, 2004.

[43] M. Saeedifar, M. Fotouhi, M. Ahmadi Najafabadi, et H. Hosseini Toudeshky, « Prediction of delamination growth in laminated composites using acoustic emission and Cohesive Zone Modeling techniques », Compos. Struct., vol. 124, p. 120-127, 2015. 


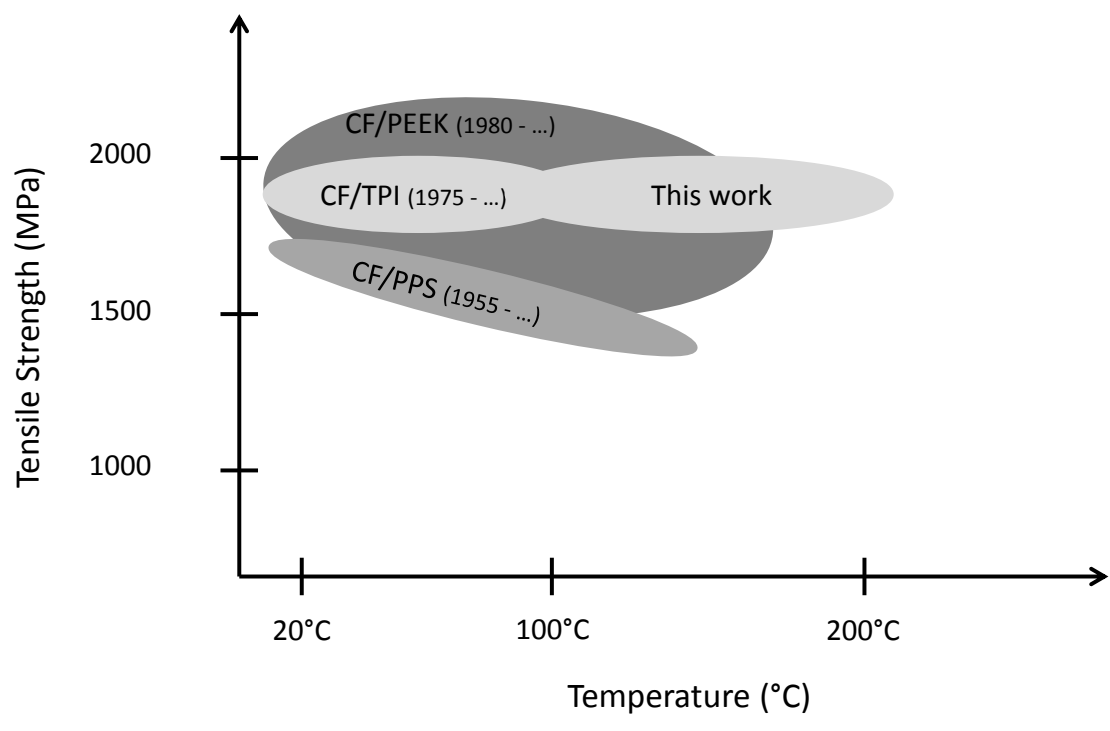

Figure 1. Typical tensile strength of thermoplastic OMCs as a function of temperature. Compilation of data reported in literature CF/PEEK [3, 4, 7, 12, 13, 15], CF/PPS [12], CF/TPI [4] and from this work.

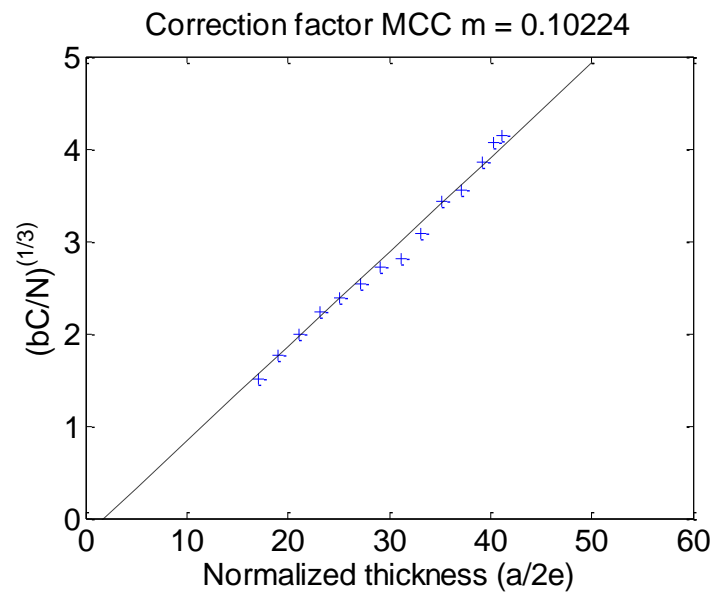

Figure 2. Illustration of the determination by linear regression of the correction coefficient " $m$ " of the MMC method for DCB tests.

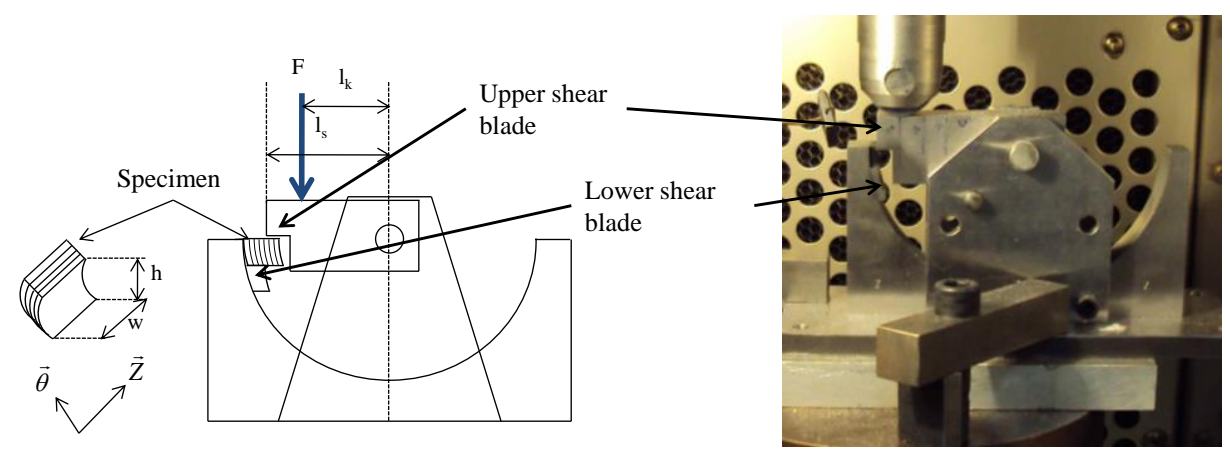

Figure 3. Home made device for interlaminar shear strength measured on curved specimen. 


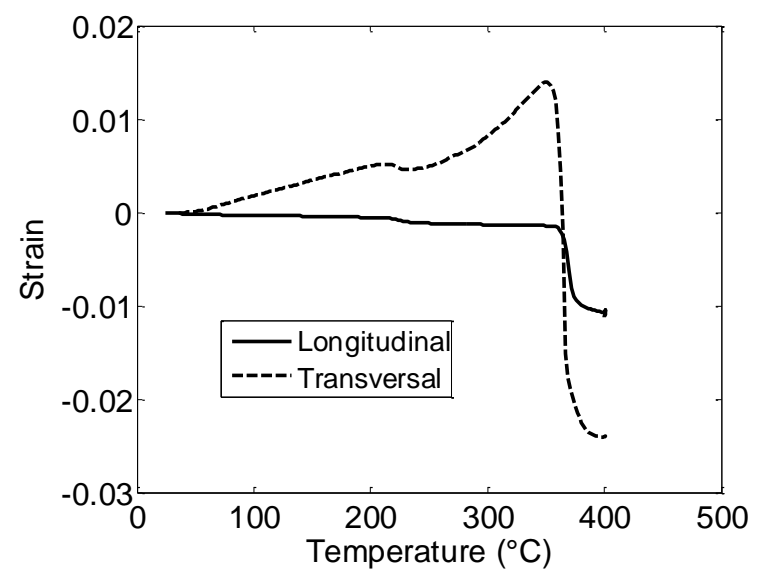

Figure 4. Thermal expansion as a function of temperature for one of the tested specimens for each composite direction. Values of CTE determined using linear regression on a temperature range $50-200^{\circ} \mathrm{C}$ :

$\alpha_{1}=-1.710^{-6} /{ }^{\circ} \mathrm{K}, \alpha_{\mathrm{t}}=3010^{-6} /{ }^{\circ} \mathrm{K}$

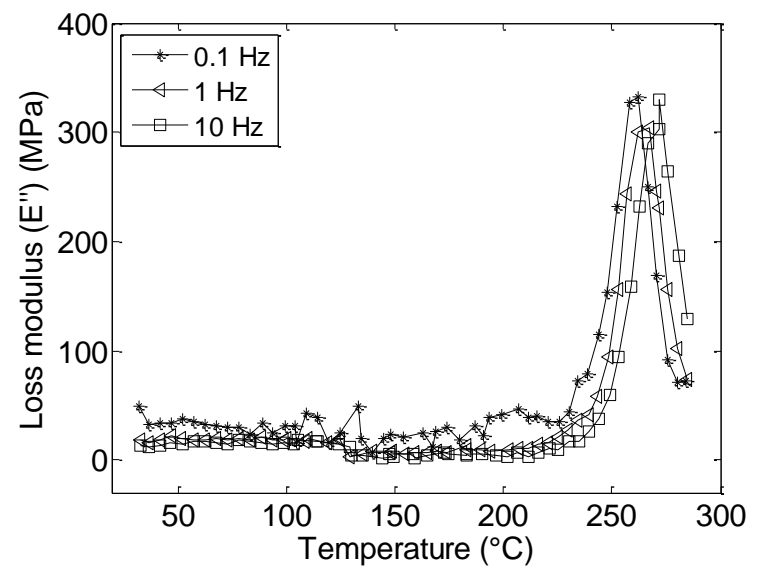

Figure 5. Loss modulus as a function of temperature, for one of the tested specimens. Identification of glass transition temperature using the peak of loss modulus. 
(a)

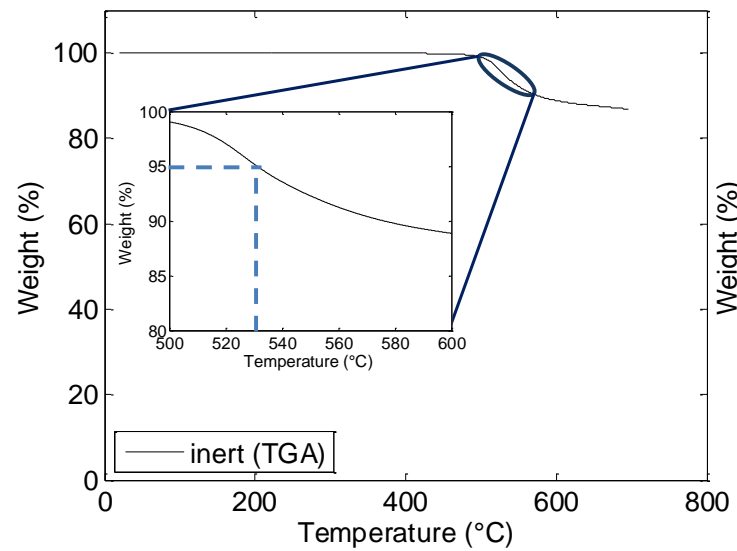

(b)

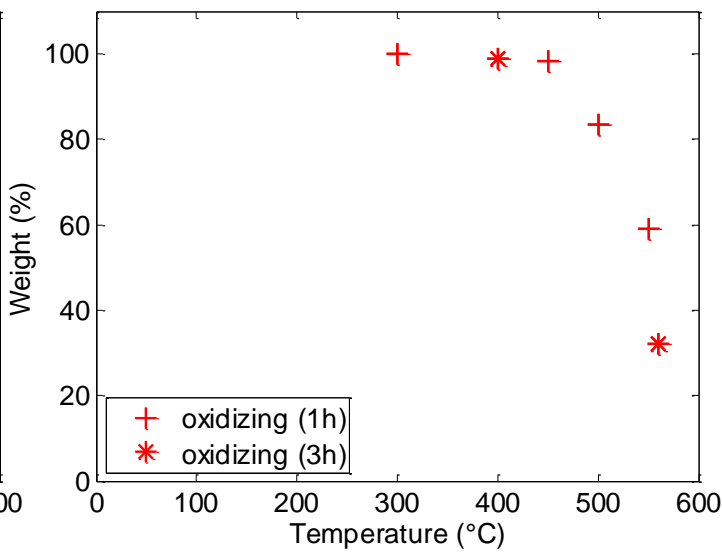

Figure 6. Weight loss of material in inert (a) and oxidizing (b) environments as a function of temperature and time of exposure.

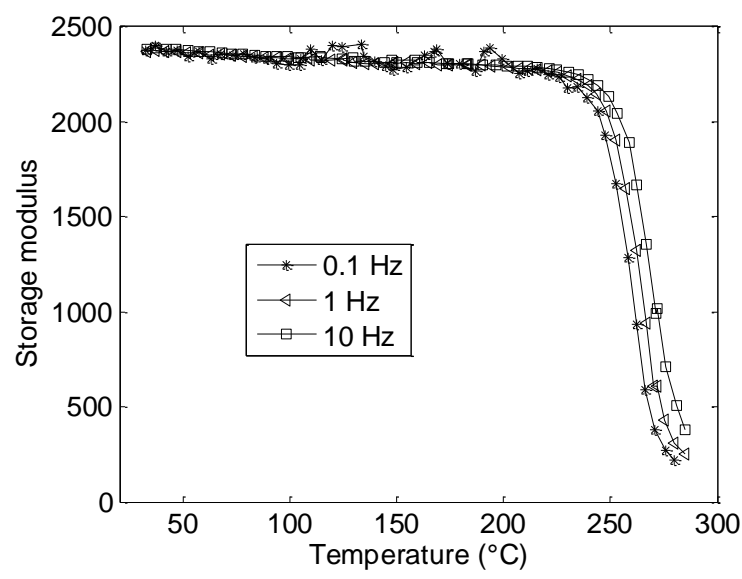

Figure 7. Storage modulus as a function of temperature, for one of the tested specimens, measured in transversal direction at 3 frequencies for $[0]_{10}$ laminate.

(a)

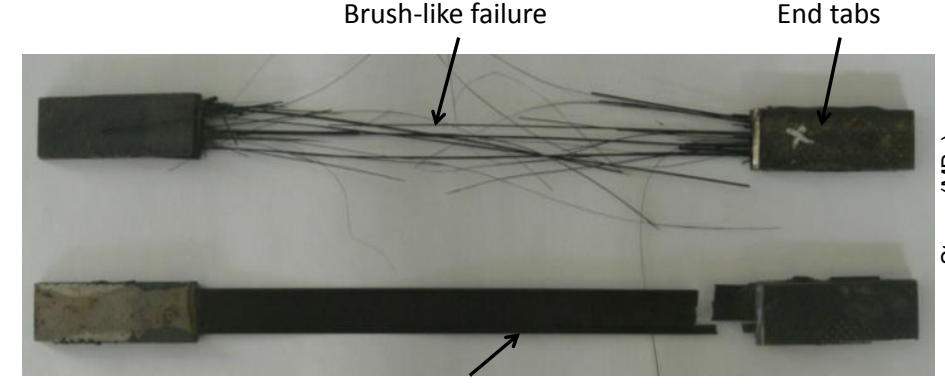

Cascade-like failure (b)

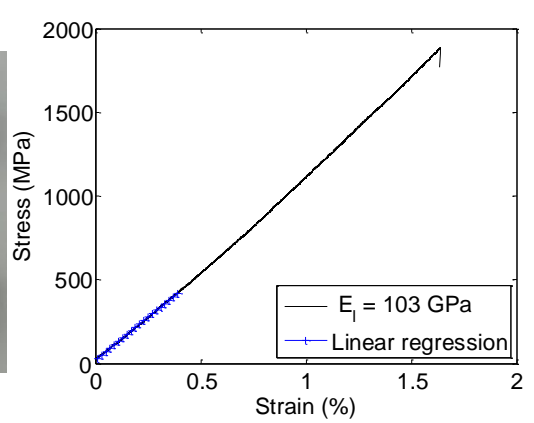

Figure 8. (a) Types of rupture observed in quasi-static tensile tests, (b) typical stress/strain curve mesured at $23^{\circ} \mathrm{C}$ in the fibre direction. 
Thermoplastic

Polyimide

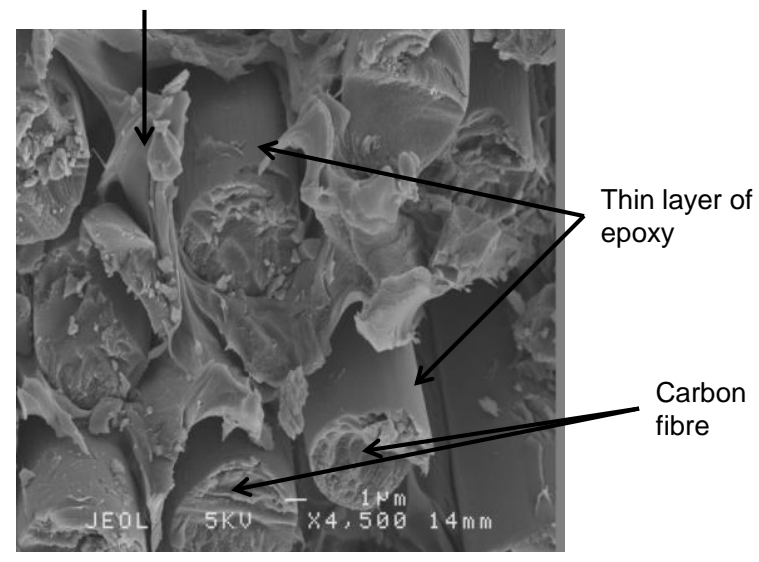

Figure 9. SEM picture after composite cryofracture. Sizing agent layer is pointed out.

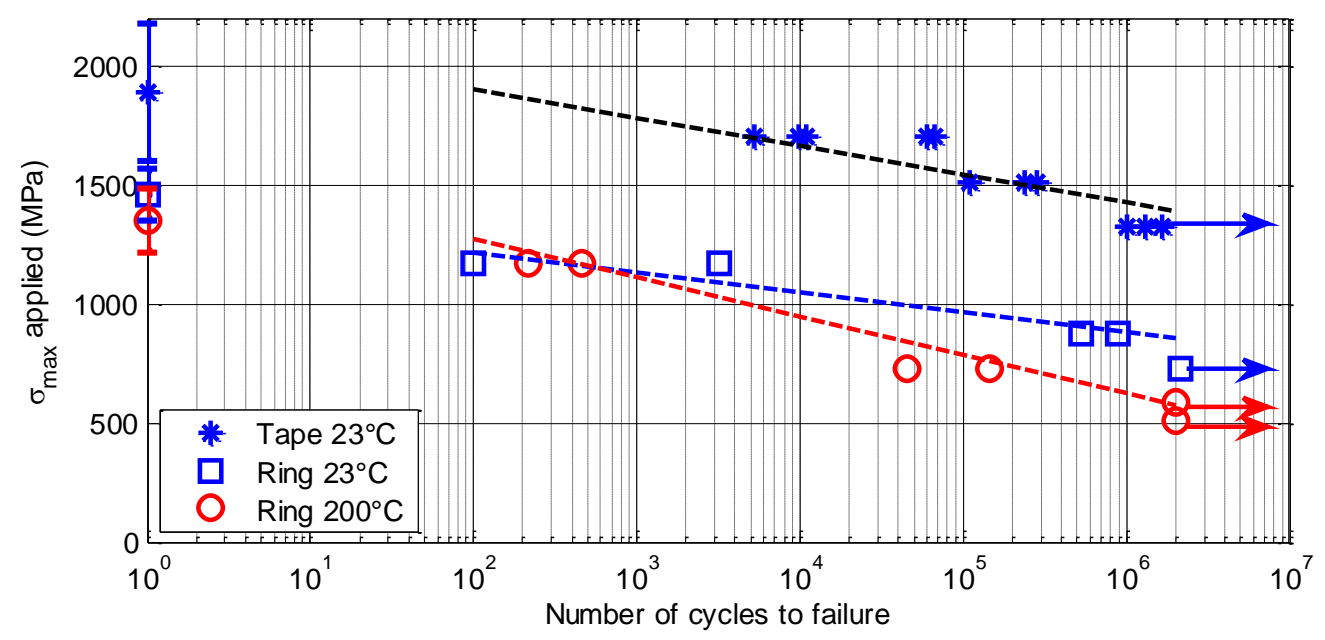

Figure 10. $\mathrm{S}-\mathrm{N}$ curve in tensile-tensile fatigue tests at $6 \mathrm{~Hz}$ and $\mathrm{R}=0.1$ for tape specimens and $5 \mathrm{~Hz}$ and $\mathrm{R}=0.2$ for ring-shaped specimens at ambient and $200^{\circ} \mathrm{C}$.

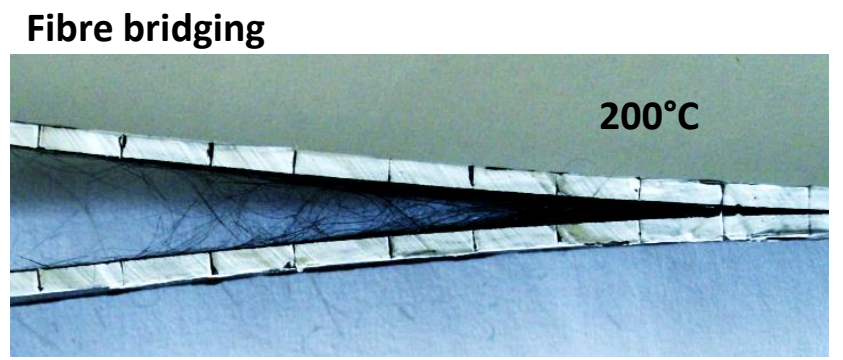

Figure 11. Observation of fibre bridging at $200^{\circ} \mathrm{C}$, during DCB tests. 